\title{
Renovation of Flat Roofs without the Need to Remove the Existing Roof Deck
}

\author{
Lukáš Janda, Marek Kervitcer, Vladimír Tichomirov, and Jiř́ Rozsypal
}

\begin{abstract}
The solution principle: „Renovation of flat roofs without the need to remove the existing roof deck" is based on the calculation procedure of $W$. van der Spoela, based on the point or line perforation, when diffusion-open termination of the new waterproofing layer allows expansion of the water vapor from the existing layers. It leads to the improvement of the thermal-technical properties of the original thermal insulation during a short time. The aim of the whole project is to create complex methodology enabling sophisticated approach to the design solution for the repair or renovation of roof deck without the need for their complete remove. The project leads to considerable cost saving and loads by reduce of ecological loads by landfilling or waste disposal.
\end{abstract}

Index Terms - Flat roof, renovation, perforation, moisture, waterproofing layer, reconstruction, roof deck, thermal insulation layer

\section{INTRODUCTION}

Defects and failures in the building industry are often caused by the synergy of multiple negative factors, the source of which lies either in the preparation, design, construction or utilisation phases [1].

With the use of sophisticated calculation procedures and proposed methodologies it is possible to predict the development of characteristics of roof deck after repairs have been done. In particular the development moisturebased parameters until an equilibrium condition are met, which allow repairs to the existing damp proof course without the need to remove the existing roofing layers. The benefit of this approach lies in the possibility of defects removal at a minimal cost [2].

\section{RENOVATION OF FLAT RoOFS Without THE NEED TO REMOVE THE EXISTING ROOF DECK}

The most frequent reasons for a renovation of roof decks are faults in the waterproofing layer which lead to penetration of rainwater into the roof deck and the interior. At present, the reasons also include energy savings resulting in a substantial increase in the thermal insulating properties of the roof deck and thus in a significant increase of the thermal insulation thickness [3].

In the case of faults in the waterproofing layer, the waterproofing layer is always exposed to the action of

Manuscript received September 25, 2018, revised May 10, 2019.

Lukáš Janda and Marek Kervitcer are with Brno University of Technology, Faculty of Civil Engineering, Brno, Czech Republic (email:janda.1@fce.vutbr.cz, kervitcer.m@fce.vutbr.cz).

Vladimír Tichomirov is with ROMEX s.r.o., Brno, Czech Republic (email: tichomirov@ romex.cz).

Jiří Rozsypal is with RKNT expert consultancy s.r.o., Brno, Czech Republic (e-mail: trozsypal@rknt.cz). rainwater penetrating the roof deck at the point of fault and an increase of the waterproofing layer moisture content also around the fault by conveying moisture in the roof deck layers [3].

In such cases, basically, the method of complete removal of the existing roof deck as far as the supporting roof structure and creating new roof deck layers has always been chosen without considering technical possibilities and with an empirically simple approach.

In the case of an interest in increasing the waterproofing properties of roof decks, the installation of additional layers made of moisture-resisting and frost-resistant

materials - usually extruded polystyrene - over the existing waterproofing layers is abandoned. This was a trend about 10 to 20 years ago. Disadvantages of this solution appeared gradually and they led to a reduction of this solution. And so also the increase of the waterproofing properties of the roof deck, even due to possible faults or a shorter life of the waterproofing layer, is proposed with removal of the existing roof deck and its replacement with new layers. [3].

Both methods with removal of the existing roof deck mean a substantial prolongation of the time of implementation, labor intensity increase, demanding handling of the removed material, its transport to dumps or to incineration plants and the price for its disposal, which altogether means a high increase in financial costs. Not omissible is also a high risk of threatening the operation in the interior caused by a possible leakage during implementation or extra costs for temporary measures against leaks.

In both cases we see the possibility of a technically and cost optimal solution in retaining the existing layers of roof decks based on a sophisticated approach to an analysis of the current state and building and physical calculations for a solution proposal. A common problem is an increased moisture of the waterproofing material, whether caused by direct leaks through defects in the waterproofing layer or by water vapor condensation. On the basis of taking samples from probes, an analysis of their actual moisture content and thermal-technical calculations using the theory Spoel 2008 [4] it is possible to propose the size of perforation holes and the perforation geometry of the existing waterproofing layer and the installation of a new waterproofing layer on it or in combination with an additional waterproofing layer. Technologically, new layers must be made in such a way that they allow conveying water vapors to the surrounding atmosphere and thus the gradual drying of the existing waterproofing layer to its equilibrium moisture content [5], [6]. 


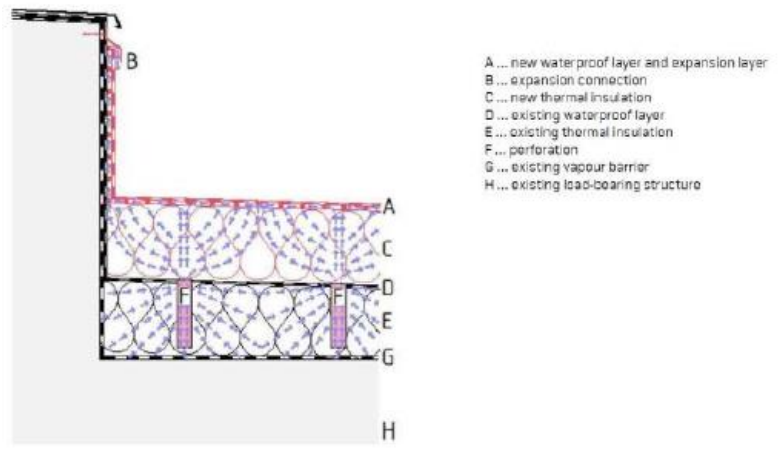

Fig. 1. The principle renovation of flat roofs without the need to remove the existing roof deck [7].

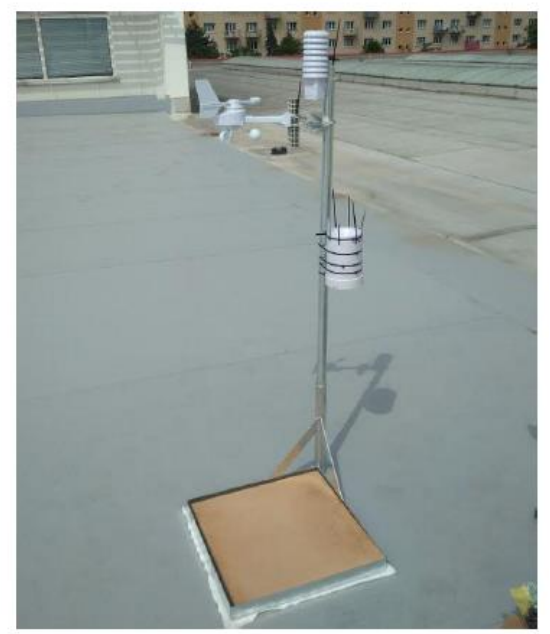

Fig. 2. The technical station for monitoring of humidity and temperature in roof deck and exterior.

According to the theoretical calculations and experience from practical applications by ROMEX s.r.o. it can be stated that the drying of a waterproofing layer, if its moisture content did not exceed $25 \%$ by weight, is a matter of two to four years until the equilibrium moisture content is reached. The authors now specify in detail these values for different humidities, perforation types, individual layers etc. in stationary and non-stationary software. The authors compare the result of both programs with the results measured experimentally to find the optimal tool for this methodology [2].

The company Romex renovated in last year this way several flat roof. The measuring equipment was installed within renovation for online monitoring of humidity and temperature with the function to verify the computational model. The monitoring is intended for three years after renovation.

\section{THEORETICAL ISSUES}

The following theoretical apparatus is based on the building-physical and thermal-technical formulations clearly elaborated to the designed issue Spoel [4] and Schüle, Reichardt [8]. At this point, only the key passages of the entire theoretical solution are extracted, when the total resistance of the composition can be obtained as a sum of the partial resistances of individual layers.

$$
\begin{aligned}
& Z_{1}=\frac{1}{\pi \times \delta} \times\left[\mu_{1} \times\left(\frac{5}{6 \times r_{s}}-\frac{1}{2 \times r_{1, s}}\right)+\mu_{2} \times\left(\frac{5}{6 \times r_{s}}-\frac{1}{2 \times r_{2, s}}\right)\right. \\
& \left.+\frac{\mu_{g} \times d_{f}}{r_{s}^{2}}\right]
\end{aligned}
$$

where $\mu_{1}=$ the diffusion resistance factor of materials under waterproofing layer $(-) ; \mu_{g}=$ diffusion resistance factor in the area of perforation (-); $\mu_{2}=$ diffusion resistance factor of materials over waterproofing layer (-); $\delta=$ diffusion conductivity coefficient $(\mathrm{s}) ; \quad d_{f}=$ waterproofing layer thickness (m); $d_{1}=$ thickness of the layer over/under waterproofing layer $(\mathrm{m}) ; \quad r_{s}=$ emisphere radius over/under perforated hole $(\mathrm{m})$



Fig. 3. Example of a regular distribution of gaps in a foil. The distance between the gaps is $2 r_{d}$ and the radius of each gap is $r_{g}$

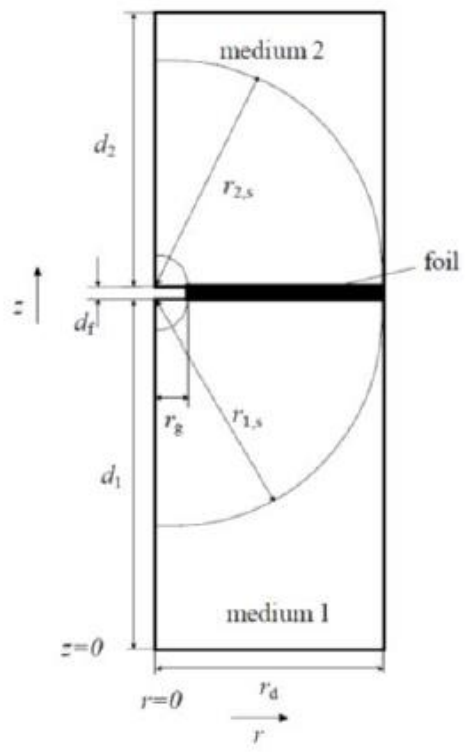

Fig. 4. Schematic representation of the cylindrical problem domain. A vapour-tight foil with thickness df is situated between two media with thickness d1 (lower side) and d2 (upper side). The foil has a cylindrical gap with radius $\mathrm{rg}$. The problem domain radially extents to $\mathrm{rd}$, halve of the typical gap-to-gap distance of the perforated foil.

The effective diffusion resistance factor of perforated foil.

$$
Z_{\text {tot }, \text { eff }}=\frac{\mu_{1} \times r_{d}+\mu_{p e r} \times d_{f}+\mu_{2} \times r_{d}}{\pi \times \delta \times \mathrm{r}_{\mathrm{d}}^{2}}
$$

where $\mu_{1}=$ the diffusion resistance factor of materials under waterproofing layer $(-) ; \mu_{p e r}=$ diffusion resistance factor of waterproofing layer $(-) ; \mu_{2}=$ diffusion resistance factor materials over waterproofing layer (-); 
$d_{f}=$ waterproofing layer thickness $(\mathrm{m}) ; r_{d}=$ distance between perforation holes $(\mathrm{m}) ; \delta=$ diffusion conductivity coefficient (s).

Other sophisticated calculations lead to a design of the size and geometry of perforations.

The calculation according to Van der Spoel can be applied if the perforation area does not exceed $5 \%$ of the undisturbed area size. In such case, the numerical calculation deviation is up to $15 \%$ from experimental measurements. In the case of a perforation design where the distance between holes is several times greater than the size of the hole alone $r_{d} \gg r_{g}$, then it is possible to use the approximation.

$$
\mu_{p e r} \times d_{f}=\frac{r_{d}^{2}}{r_{g}} \times\left(\frac{5 \times \mu_{1}}{6}+\frac{5 \times \mu_{2}}{6}+\frac{\mu_{g} \times d_{f}}{r_{g}}\right)
$$

To express the perforation size value, we will perform substitution and will adjust the relation to the following form:

$$
=\frac{r_{g 1,2}}{-\left(\frac{5 \times \mu_{1}}{6}+\frac{5 \times \mu 2}{6} \pm \sqrt{\left(\frac{5 \times \mu_{1}}{6}+\frac{5 \times \mu_{2}}{6}\right)^{2}-\frac{4 \times \mu_{g} \times \mu_{p e r} \times d_{f}^{2}}{r_{d}^{2}}}\right)}
$$

If the condition if fulfilled

$$
\left(\frac{5 \times \mu_{1}}{6}+\frac{5 \times \mu_{2}}{6}\right)^{2}-\frac{4 \times \mu_{g} \times \mu_{p e r} \times d_{f}^{2}}{r_{d}^{2}}>0
$$

Then the final relation for the calculation of perforation size has the following form.

$$
r_{g 1,2}=\frac{2 \times \mu_{g} \times d_{f}}{\sqrt{\left(\frac{5 \times \mu_{1}}{6}+\frac{5 \times \mu_{2}}{6}\right)^{2}-\frac{4 \times \mu_{g} \times \mu_{p e r} \times d_{f}^{2}}{r_{d}^{2}}}-\left(\frac{5 \times \mu_{1}}{6}+\frac{5 \times \mu_{2}}{6}\right)}
$$

From the calculated perforation size, we can use other calculations to find out the distance between holes [1].

\section{REDUCE OF MOISTURE CONTENT BY THE INFLUENCE OF PERFORATION THE EXISTING LAYERS}

Currently, spread of moisture is evaluated in practice by Glaser method which neglected some non-stationary phenomena for more exact spread of moisture. The Glaser method uses one material characteristic which is diffusion resistance factor [1].

The authors calculated reduce of moisture content four composition of flat roof with perforation the existing layers (Fig. 5) in stationary program by W. van der Spoel's theory. The new layers of the flat roof are marked in red, the existing layers are black [9].

The four composition of flat roof was modeled with $5 \%$ moisture content $M a=0,3 \mathrm{~kg} / \mathrm{m}^{2}$ in existing (original) insulation and $48 \%$ perforation from area of flat roof.

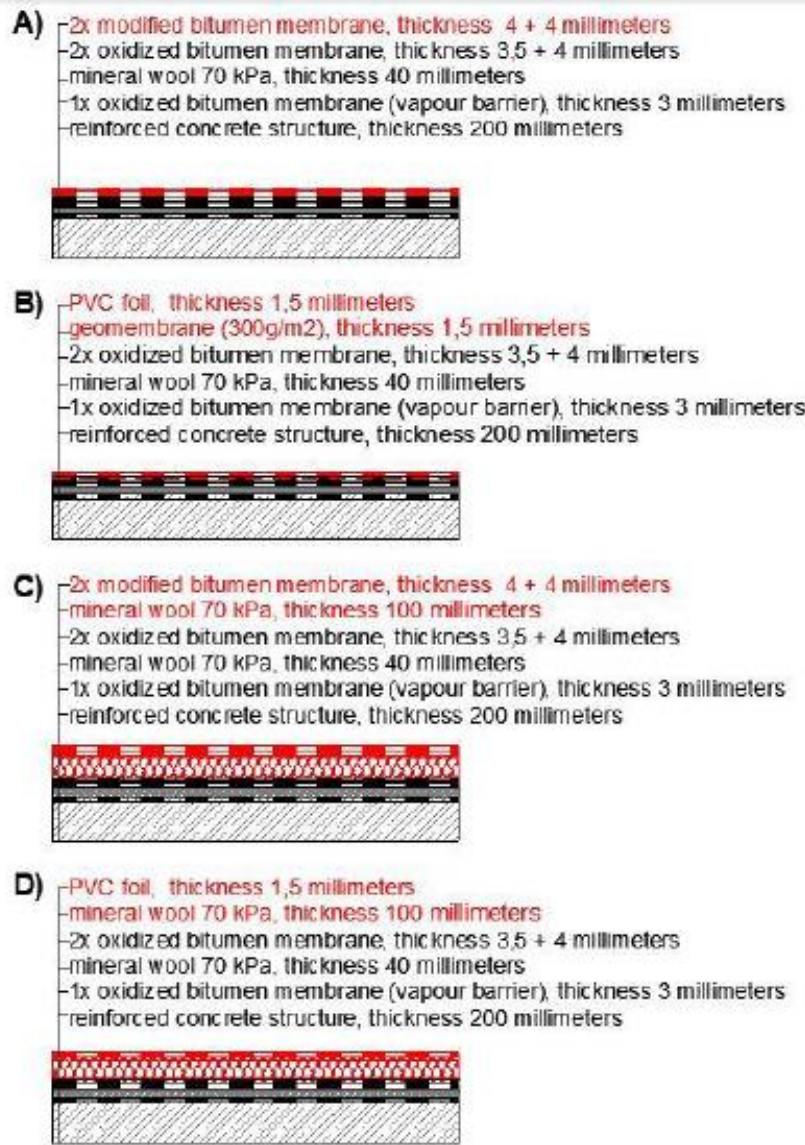

Fig. 5. The schema of four composition of flat roof



Fig. 6. The graph of reduce of moisture content in existing insulation on four composition by the influence of the perforations after one year completed repair of flat roof.

The results by Fig. 6 show graph of reduce of moisture content in existing insulation after one year completed repair of flat roof.

The results by Table I show specific numbers of reduce of moisture content in existing insulation after one year completed repair of flat roof.

TABLE I: THE SPECIFIC NUMBERS OF REDUCE OF MOISTURE CONTENT IN EXISTING INSULATION ON FOUR COMPOSIONS BY THE INFLUENCE OF THE PERFORATIONS AFTER ONE YEAR COMPLETED REPAIR OF FLAT ROOF

\begin{tabular}{ccccc}
\hline \hline Composition & $\mathrm{A}$ & $\mathrm{B}$ & $\mathrm{C}$ & $\mathrm{D}$ \\
\hline $\begin{array}{c}\text { Moisture } \\
\text { content } \\
\mathrm{Ma}\left(\mathrm{kg} / \mathrm{m}^{2}\right)\end{array}$ & 0,2071 & 0,2280 & 0,2773 & 0,3261 \\
\hline \hline
\end{tabular}

The results from stationary program show reduce of moisture content by the influence of the perforations. The results show influence kind of new layers and thickness of 
new layers for reduce of moisture content in roof layers.

The authors calculated these four compositions and the next specific composition by non-stationary program, where they used diffusion resistance factors of layers by W. van der Spoel's theory. Comparison of results by non-stationary program and stationary program will be interesting [9], [10].

\section{ECONOMICAL ASPECT}

Besides the theoretical and technical solution, the project deals with the economic aspects leading to a successful project. Paradigmatic calculation is shown below based on prices from Czech Republic.

\section{A. Renovation with Complete Removal}

Renovation with complete removal include removal, transportation and disposal of existing roof deck with these costs:

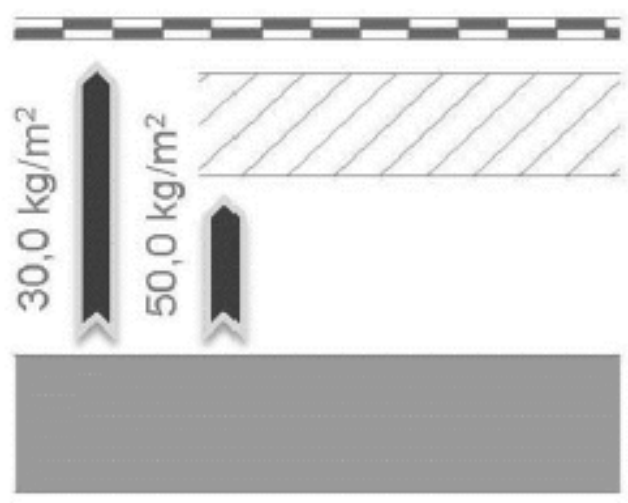

Fig. 7. The renovation with complete removal - disposal of existing roof deck.

$\begin{array}{lrl}\text { Waterproofing } \quad 30 \mathrm{~kg} / \mathrm{m}^{2} & 12,8 € / \mathrm{m}^{2} \\ \text { Roof layers } \quad 50 \mathrm{~kg} / \mathrm{m}^{2} & 11,5 € / \mathrm{m}^{2} \\ \text { Adjustment after removal } & \\ \underline{6,5 € / \mathrm{m}^{2} \approx \mathbf{3 0 , 8} € / \mathbf{m}^{\mathbf{2}}} & \end{array}$

Next step after removing existing layers is installation of new roof deck:



Fig. 8. The renovation with complete removal - installation of new roof deck.

$\begin{array}{llr}\text { Vapour barrier } & 4,5 \mathrm{~kg} / \mathrm{m}^{2} & 7,8 € / \mathrm{m}^{2} \\ \text { Insulation (t. 200 } \mathrm{mm}) & 6,0 \mathrm{~kg} / \mathrm{m}^{2} & 20,6 € / \mathrm{m}^{2} \\ \text { Waterproofing } & 2 \times 4,5 \mathrm{~kg} / \mathrm{m}^{2} & 26,4 € / \mathrm{m}^{2} \\ & & \underline{\mathbf{5 4 , 8} € / \mathbf{m}^{2}} \\ & \text { Overall costs } & \mathbf{\approx \mathbf { 8 5 , 6 }} / \mathbf{m}^{2}\end{array}$

\section{B. Renovation without complete removal}

In this case is only surface adjustment and perforation the existing layers with these costs:

Surface adjustment + perforation

$$
\approx \frac{3,5 € / \mathrm{m}^{2}}{\mathbf{3 , 5} € / \mathrm{m}^{2}}
$$

Next step after surface adjustment and perforation is installation of new roof deck:



Fig. 9. The renovation without complete removal - installation of new roof deck on existing layers.

$$
\begin{array}{llr}
\text { Insulation (t. } 150 \mathrm{~mm}) & 4,5 \mathrm{~kg} / \mathrm{m}^{2} & 13,6 € / \mathrm{m}^{2} \\
\text { Waterproofing } & 2 \times 4,5 \mathrm{~kg} / \mathrm{m}^{2} & 26,4 € / \mathrm{m}^{2} \\
& & \approx \mathbf{4 0 , 0} € / \mathbf{m}^{\mathbf{2}} \\
& \text { Overall costs } & \approx \mathbf{4 3 , 5} € / \mathbf{m}^{\mathbf{2}}
\end{array}
$$

The price is reduced from $85,6 € / \mathrm{m}^{2}$ to $43,5 € / \mathrm{m}^{2}$. The practical benefit of this renovation method is a cost reduction by about 50\% compared to a renovation with removal of the existing roof deck. These saved funds can then be used for the purpose of investments in the architectonic design of a flat roof or for other preferred user purposes related to the flat roof renovation. [11], [12].

\section{ENVIROMENTAL ASPECT}

Total Area of reconstructed roofs in Czech Republic is presumes 1,5 million $\mathrm{m}^{2} /$ year. Waste not deposited in landfills can reach approximately 100-120 million ton per year. The most problematic aspect is that when completely dismantled as described above, the waste is 80 $\mathrm{kg} / \mathrm{m}^{2}$ of that is least $30 \mathrm{~kg} / \mathrm{m}^{2}$ dangerous waste. For this reason this methodology has important ecological value.

\section{CONCLUSION}

The aim of the whole project is to create complex methodology enabling sophisticated approach to the design solution for the repair or renovation of roof deck without the need for their complete remove. The authors extend W. van der Spoel's theory about series of calculations and measurement.

The project leads to considerable cost saving and reducing of ecological loads by landfilling or waste disposal. The authors will pass the methodology into company Romex s.r.o, which will use it for increase of their market excellence.

With this paper, we would like to welcome the interest of other universities working on this issue and company Romex offers cooperation to all investors and other 
interested parties.

\section{ACKNOWLEDGMENT}

Contribution to the conference was created within the OP EIC project No. CZ.01.1.02 / 0.0 / 0.0 / 16_054 / 0009229 "Reduction of costs of repairs and reconstructions of flat roofs and elimination of the effects of roofs on the environment" supported by the Ministry of Industry and Trade of the program "OP PIK - PO 01 Development of research, development and innovation" and within the project supported by the Minister of Industry and Trade under No. LO1408 "AdMaS UP - Advanced Building Materials, Structures and Technologies" supported by the Ministry of Education, Youth and Sports targeted support for the "National Sustainability Program I."

\section{REFERENCES}

[1] M. Kervitcr, L. Janda, D. Bečkovský, and V. Tichomirov, "Renovation offlat roofs without the need to remove the existing roof deck," in Proc. the 9th International Conference Building Defects, 2017

[2] V. Tichoirov, "The prediction of the building-physics performance of flat roofs," Shortened Version of Habilitation Work, Brno University of Technology, 2019.

[3] V. Tichomirov, K. Landl, and D. Bečkovský, "Reconstruction of roof decks of large roofs as a result of a synergy between technical and architectural solutions," 2016.

[4] W. V. D. Spoel, Water Vapour Transport Through Perforated Foils, 2008.

[5] EN ISO 12572: 2001 Hygrothermal performance of building materials and products - determination of water vapour transmission properties, CEN, 2001.

[6] ASTM E 96/E 96M, Standard Test Methods for Water Vapor Transmission of Materials, West Conshohocken: ASTM International, 2005.

[7] P. Slanina. Moisture transport in compact flat roofs. [Online]. Available:

http://www.slanina.cz/publikace/files/27_slanina_moisture_transport_ in_compact_flat_roofs.pdf

[8] W. Schüle and I. Reichardt, "Wasserdampfdurchgang durch öffnungen.wksb-so," 1980.

[9] M. Kervitcer and L. Janda, "Reduce of moisture content by the influence of the perforations of in roof layers," presented at the 42nd Meeting of the Institute of Building Construction and Departments of Building Structures of the Czech and Slovak Republics R\&D activities of PhD students in the Czech Republic and Slovakia, 2019.

[10] H. M. Künzel, "More moisture load tolerance of construction assemblies through the application of a smart vapor retarder," in Proc. Thermal Envelopes VII (pp.129-132). Clearwater Beach: ASHRAE, 1998.
[11] C. Tito, S. José, B. Jorge, and G. Raul, "Lifecycle cost analysis of flat roofs of buildings," Journal of Construction Engineering and Management, vol. 143, 2017.

[12] M. Kervitcer, L. Janda, V. Tichomirov, and D. Bečkovský, "Economic comparison of methodological processes of roof layers removing," Forensic Engineering, vol. 30, no. 1, pp. 17-21, 2019.

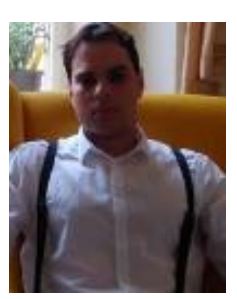

of Technology.
Lukáš Janda is an engineer in the field of civil engineering of the master's degree program at the Faculty of Civil Engineering of the Brno University of Technology and $\mathrm{PhD}$ student at the Institute of Building structures, Faculty of Civil Engineering, Brno University of Technology.

He deals with the design of buildings and flat roofs. $\mathrm{He}$ works as a researcher at the AdMaS Research Center, Faculty of Civil Engineering, Brno University



Marek Kervitcer is an engineer in the field of civil engineering of the master's degree program at the Faculty of Civil Engineering of the Brno University of Technology and $\mathrm{PhD}$ student at the Institute of Building structures, Faculty of Civil Engineering, Brno University of Technology. He deals with the design of buildings and the issue of building insulation with a focus on roofs. He has been working in the realization sphere. He worked as a researcher at the AdMaS Research Center, Faculty of Civil Engineering, Brno University of Technology. He works as a technician in the construction company Romex s.r.o.

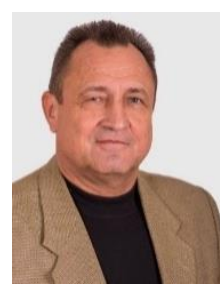

Vladimír Tichomirov is a authorized engineer and expert forensic expert in the field of civil engineering, $\mathrm{PhD}$ graduate of the Faculty of Civil Engineering of the Brno University of Technology and actualy student at the Institute of Law and Legal Sciences o.p.s. He deals with the issue of building insulation with a focus on flat roofs.

$\mathrm{He}$ is the owner and director of a construction company Romex s.r.o. and Expert office Tichomirov.



Jiří Rozsypal is a authorized engineer in the field of civil engineering, graduate of the master's degree program at the Faculty of Civil Engineering of the Brno University of Technology and specialized studies at the Institute of Forensic Expertise of the Brno University of Technology, a PhD student at the Institute of Building structures, Faculty of Civil Engineering, Brno University of Technology. He deals with the issue of building insulation with a focus on roofs and ventilated facades. Since 2004 he has been working in the realization sphere in the field of waterproofing of buildings and is the executive of RKNT expert consultanty s.r.o. 